\title{
A Review of the Impact and Coping Methods of Abusive Supervision on Employees
}

\author{
Wenzhuo Zou \\ School of Management, Jinan University, Guangzhou, China \\ Email: 13574084068@163.com
}

How to cite this paper: Zou, W.Z. (2020) A Review of the Impact and Coping Methods of Abusive Supervision on Employees. Open Journal of Business and Management, 8, 713-725.

https://doi.org/10.4236/ojbm.2020.82043

Received: February 18, 2020

Accepted: March 15, 2020

Published: March 18, 2020

Copyright $\odot 2020$ by author(s) and Scientific Research Publishing Inc. This work is licensed under the Creative Commons Attribution International License (CC BY 4.0).

http://creativecommons.org/licenses/by/4.0/

\section{(c) (i) Open Access}

\begin{abstract}
In reality, abusive supervision will bring many problems to organization governance. With the deepening of research on this management style, the related researches of abusive supervision are constantly developing. From the perspectives of specific research content and methods, this paper summarizes the relevant literatures on the impact and coping methods of abusive supervision on employees. The results of these studies show that abusive supervision has a negative impact on employee innovation and performance, satisfaction and emotions, and knowledge sharing, while it is positively related to employee deviance or anti-productive behavior and turnover intentions. In addition, employee psychological changes can bring positive effects to abusive supervision, and the active expression of subordinates and the good communication with superiors are both effective ways to deal with the problems of abusive supervision. However, the existing research system in these areas is still incomplete. Future research can systematically research the impact and coping methods of abusive supervision in organizations from the level of individuals, teams, and organizations.
\end{abstract}

\section{Keywords}

Abusive Supervision, Innovation and Performance, Employee Behavior, Coping Methods

\section{Introduction}

In recent years, the issue of abusive supervision in organizations has gradually attracted more attention; it has become a hot issue in the field of organizational behavior, and continually some new features and new results emerge. 
In the term of theoretical research on abusive supervision, researchers generally agree with the expression of the concept of abusive supervision by Tepper [1], that is, abusive supervision is a kind of destructive leadership behaviors existing in various organizations, which refers to a subordinate's perception of linguistic or non-verbal hostile behavior that is consistently displayed by a supervisor, but does not include physical contact. Later, research on various aspects of abusive supervision has gradually developed and enriched, from the definition of abusive supervision to the measurement, causes, consequences, and mechanisms of abusive supervision, and then to its response mechanism and certain degree of positive effect. The whole research process of abusive supervision is continuously deepening and expanding.

Based on the related research on the theory of abusive supervision, this paper reviews the relevant literature, summarizes the research results and characteristics of abusive supervision, and finds its future research space, in order to improve the research systems of abusive supervision and address abusive supervision issues in organizations in practice. On the whole, this paper summarizes the main research content, research methods, research deficiencies, and research prospects of abusive supervision. At present, many researches focus on the relationship between abusive supervision and the relevant characteristics of employees. Therefore, the focus of this paper is to analyze the two aspects of the impact of abusive supervision on employees and coping methods of abusive supervision, so as to roughly grasp the key points and characteristics of each study, and to summarize and evaluate. In content, this paper summarizes the relevant literatures on the impact and coping methods of abusive supervision on employees and puts forward the specific research direction in the future. The rest of this article is organized as follows: the second section mainly reviews and summarizes the researches on the impact of abusive supervision on employees; the third section mainly reviews and summarizes the researches on the coping methods of abusive supervision; the fourth section mainly reviews and summarizes the main research methods of related literature; the fifth section mainly summarizes the conclusions, main contributions of this paper and the prospects of future research.

\section{Research on the Impact of Abusive Supervision on Employees}

In the term of research on the impact of abusive supervision, in general, many studies have explored the interrelationship of abusive supervision and employee-related factors at the employee level. In summary, these studies basically analyze the interrelationships between abusive supervision and employee innovation and performance, employee satisfaction and emotion, employee knowledge sharing, employee deviance or anti-productive behavior, employee turno-

ver intentions. On this basis, researchers not only studied the negative impact of abusive supervision on employees, but also began to pay more attention to the positive impact of abusive supervision. 


\subsection{Abusive Supervision and Employee Innovation and Performance}

In the term of the impact of abusive supervision on employee's innovation and job performance, most results of researches basically show that abusive supervision has a negative impact on employee creativity and performance, but the mediation and moderating factors in these relationships are different. For example, Lee et al. [2] explored the possibility of a curvilinear relationship between abusive supervision and employee creativity using activation theory, and used a hierarchical regression curve to analyze the relationship between abusive behaviors of supervisors and creative performance of employees: when abusive supervision is at a medium level rather than at a very low or very high level, employees show more creativity. Khusbu et al. [3] explored the impact of abusive supervision on employee creativity. Based on social cognitive theory, the study shows that abusive supervision is negatively related to employee creativity, and the creative self-efficacy plays a full mediating role in this relationship. In addition, the employee's power distance orientation plays a moderating role. When the power distance tends to be high, the direct impact of abusive supervision on creative self-efficacy and the mediating effect of creative self-efficacy are weak, so employee creativity can be enhanced by enhancing employees' confidence in their ability to succeed. Lyu et al. [4] found that abusive supervision negatively affects employees through organizational identity based on social identity theory. In addition, employee collectivism strengthens the impact of abusive supervision on organizational identification. When employees show a high degree of collectivism, this relationship is stronger, which indicates that the level of employee collectivism may exacerbate abusive supervision.

However, some China's researches in this area have researched and analyzed the mechanism of abusive supervision on job performance and introduce in China's specific cultural background and corporate environment, and introduce different mediating variables to explain the relationship based on different theoretical perspectives. For example, Gao He et al. [5] studied the impact and role of abusive supervision on job performance in China's high right distance and high collectivist cultural environment based on a two-factor theoretical basis. The research results show that abusive supervision has a significant negative impact on job performance; employee job satisfaction plays a part in the mediating role in this process; the core self-evaluation negatively regulates the impact of abusive supervision on employee job satisfaction. Yan Aimin and Pei Cong [6] explored the impact mechanism of abusive supervision on job performance in the Chinese context from the perspective of resource conservation theory and social exchange theory. The research shows that abusive supervision has a significant negative impact on task performance and peripheral performance, and self-efficacy plays a part mediating role in the impact of abusive supervision on task performance and a fully mediating role in the impact of abusing management on peripheral performance. Yu Weina et al. [7] revealed Chinese cultural traditions play a role in the impact of abusive supervision on job performance, 
and introduced subordinate forgiveness as core variable which used to explain how the subordinate's mental state changes from negative to positive in the impact mechanism of abusive supervision, thereby alleviating the negative effects of abusive supervision.

\subsection{Abusive Supervision and Employee Satisfaction and Emotions}

In the term of the impact of abusive supervision on employee satisfaction and emotions, researches show that abusive supervision reduces employee satisfaction and is related to employees' negative emotions. For example, Lin et al. [8] showed that abusive supervision is considered to be an important social issue that affects followers' mental health and job satisfaction. Abusive supervision can lead to poor employee benefits such as poor mental health and low job satisfaction. The research is based on the cognitive evaluation theory, which explains the follower's response to abusive supervision through the adjustment of the follower's power distance orientation, and it shows that the power distance orientation of employees significantly reduces the relationship between their mental health and job satisfaction, while the negative relationship between employees with high power orientation is weak, which shows the adaptive function of the cultural value of employees in organizational behavior. Jiang et al. [9] mainly tested the relationship between abusive supervision and professional satisfaction, and explored whether social self-efficacy mediated the relationship between abusive supervision and professional satisfaction from the perspective of social cognition, and studied the moderating role of organizational tenure and positive personality on this intermediary relationship. The research indicates that professional self-efficacy plays a mediating role between abusive supervision and professional satisfaction, while organizational tenure and positive personality weaken the main role of abusive supervision and the indirect effects of professional self-efficacy. This study deepens our understanding of the negative effects of abusive supervision. Henle and Gross [10] found that emotional stability and responsibility negatively predict employee abusive supervision according to the victim precipitation theory, and this relationship is mediated by negative emotions. Therefore, employees with lower emotional stability or sense of responsibility are more likely to experience negative emotions, which in turn is associated with higher levels of abuse. Ogunfowora [11] studied the consequences of decentralized unit level abusive supervision or abusive supervision variation. Abusive supervision variation has negative effects on employees' attitudes and behaviors through intermediary effects of interpersonal justice and atmosphere power. The research results show that abusive supervision is negatively related to the cognition of leadership ethics, organizational ethics, leadership satisfaction, and emotional commitment.

\subsection{Abusive Supervision and Employee Knowledge Sharing}

In the term of the impact of abusive supervision on employee knowledge shar- 
ing, the basic research conclusion is that there is a negative relationship between abusive supervision and employee knowledge sharing, and abusive supervision affects the degree of knowledge sharing among employees through different intermediary factors. $\mathrm{Wu}$ and Lee [12] used the theory of resource conservation to explore the impact of abusive supervision on psychological capital and the factors that affect knowledge sharing. In addition, the authors used contextual variables, namely group trust, to explore its cross-effects on the above-mentioned causality. The study conducted a multi-level analysis of knowledge sharing, in which abusive supervision and psychological capital are the determinants of individual knowledge sharing, and group trust is considered to be a group-level variable with cross-level effects. The empirical results show a negative correlation between abusive supervision and knowledge sharing. The results also show that psychological capital plays an intermediary role between abusive supervision and knowledge sharing, but at the group level, group trust has a direct cross impact on knowledge sharing of employees, which can alleviate the relationship between abusive supervision and psychological capital. Kim et al. [13] believed that knowledge sharing is essential to achieve the organization's sustainable competitive advantage, but abusive supervision may become an obstacle to personal knowledge sharing. This article used the perspective of social exchange theory to explore the impact of abusive supervision on knowledge sharing. The results of this research show that abused employees tend to hoard their knowledge, which is not conducive to knowledge sharing among employees, but organizational support can reduce this harmful effect. Kim et al. [14] used the theory of resource protection to explore the impact of destructive behavior of leaders, such as abusive supervision on employee knowledge sharing, and the role of learning goal orientation and self-improvement motivation in regulating the above relationship. The results suggest that resource-depleted and abused employees may reduce their level of knowledge sharing. In addition, the negative effects of abusive supervision may vary based on personal factors. Therefore, in order to achieve organizational effectiveness through knowledge sharing, the key role of leader behavior and employee characteristics or motivations cannot be ignored.

\subsection{Abusive Supervision and Employee Deviant or Anti-Production Behavior}

In the term of the impact of abusive supervision on employee deviance or anti-productive behavior, related researches found that abusive supervision has a positive relationship with employee's deviance, and abusive supervision can predict employees' anti-productive behavior to a certain extent. Wei and Si [15] mainly researched the interpersonal interactions perceived by employees, specifically, tested the relationship between the organization's abusive supervision and the anti-production work behavior of subordinates. This study found that abusive supervision can lead to increased levels of destruction, withdrawal, production bias, and theft. The study also examined the regulatory role of control 
points and the perceived fluidity of the relationship between abusive supervision and subordinate anti-production work behaviors in the organization. The results show that the positive correlation between abusive supervision and subordinates' anti-productive work behavior is determined by psychological control and perceived mobility. Vogel et al. [16] believed that abusive supervision is positively related to employee deviance, and public service motivation (PSM) is negatively related to deviance, so PSM may help prevent the negative impact of deviance, but this only applies to public and non-profit department employees, PSM may be positively correlated with deviance in for-profit organizations. Michel et al. [17] explored the connection mechanism and conditional process of abusive supervision and deviance in the workplace based on emotional events theory. The research results show that work-related negative emotions will mediate the abusive supervision and deviance in the workplace, and this indirect impact is conditional on employee-oriented and organization-based. Ma Yinqiu et al. [18] studied the psychological cognitive mechanism and boundary conditions of the anti-production behavior of subordinate employees based on social cognitive theory. The study found that abusive supervision has a significant positive predictive effect on employees' anti-productive behaviors, while psychological contract breaks play an intermediary role in this relationship, and employee self-construction regulates the relationship among abusive supervision, psychological contract breaks and anti-productive behaviors.

\subsection{Abusive Supervision and Employee Turnover Intention}

In the term of the impact of abusive supervision on employee turnover intentions, the studies found that abusive supervision can directly affect employee turnover intentions, and indirectly predicts employee turnover intentions through some intermediate factors, besides, there is a positive relationship between abusive supervision and employee turnover intentions. Mathieu and Babiak [19] believed that abusive supervision has a negative impact on employee and organizational performance, so they explored the underlying factors of dark leadership, and tested the relationships among corporate psychosis traits, abusive supervision, employee job satisfaction and turnover intentions. The results show that the pathological personality traits have a direct impact on abusive supervision, and the supervisor's psychological abnormal characteristic value directly affects employee turnover intention, psychopaths express their aggression in the workplace through abusive supervision behaviors. The results of these studies indicate that the dark personality of mental illness can easily lead to abusive supervision. In addition, the mental characteristics of supervisors are a good predictor of negative employee attitudes, especially turnover intentions. Palanski et al. [20] examined the role of moral leadership and abusive supervision in the process of resignation by using the information disclosure expansion model and the dual process theory of information processing. The main conclusion of this study is that ethical leadership affects job satisfaction, and then af- 
fects turnover intentions, and then affects job search behaviors. The abusive supervision, which is contrary to the concept of ethical leadership, has negative impact on job satisfaction, and also has impact on turnover intention and job search behavior. In addition, this research also shows that even low-level abusive supervision can neutralize high-level moral leadership. Xi Yanping [21] examined the effect of supervisor's abusive supervision on employee turnover intentions, and examined the multiple mediating effects of emotional exhaustion and employee trust based on the theory of social exchange and resource conservation. The result of the study is that the abusive supervision of supervisors not only directly affects employee turnover intentions, but also indirectly predicts employee turnover intentions through emotional exhaustion and employee trust.

\subsection{Positive Influence of Abusive Supervision on Employees}

With the deepening of researches on the impact of abusive supervision, researchers have gradually discovered that although abusive supervision has many negative effects on employees' work, emotions and behaviors, some studies also found that abusive supervision under specific conditions has some positive impact. Specifically, some researches explored the positive effects of abusive supervision from the perspective of the individual's response to abusive supervision. Khan et al. [22] believed that the subordinates' perception of the dangerous world and the abusive supervision are a positive correlation mediated by obedient authority figures, and this relationship is to increase the number of underperforming employees. This research emphasized the possibility of individual differences, that is, the world view, attitudes and ability levels, may cause employees to become victims of abusive supervision. Specifically, this research believed that the impact of abusive supervision is strongly related to the individual differences in employees 'perception of environmental threats. If employees' perception of environmental threats declines, they will improve their behavioral performance, thereby transforming the impact of abusive supervision into a positive effect. Thus, organizations need to focus on designing and implementing policies that allow employees to feel that their organization is not a threat to work, develop measures to improve individual employee performance, and provide clear policies and training on performance management. Decoster et al. [23] believed that although abusive supervision has a significant negative impact on employees' health, attitudes and behaviors, abuse from leaders is not always negative. This study found that organizational identity and abusive supervision interact with the cohesiveness of employees' work teams and their tendency to gossip about leaders. In the face of a highly abusive supervisor, employees have a stronger sense of identification with their organization and have less gossip. This result showed that employees do not necessarily react negatively to abusive leaders. In fact, organizational identity is a protective mechanism for the negative impact of abusive supervision. In short, in the presence of abusive supervisors, employees with high organizational identity show weaker negative reactions 
than those with low organizational identity.

\section{Research on Coping Methods of Abusive Supervision}

In the term of research on coping methods of abusive supervision, although the research in this area is still incomplete, in recent years, researchers have gradually started to focus their research on coping methods of abusive supervision. These researches mainly analyzed from two perspectives of leaders or subordinates, and studied the positive measures of the two parties when dealing with the issue of abusive supervision. For example, Harvey et al. [24] found that employees' use of ingratiation, when coupled with high levels of PA (positive affect), would neutralize the adverse effects of abusive supervision on each outcome. Harvey et al. [25] presented two studies that examine the effects of psychological entitlement on employees' ratings of abusive supervision and their behavioral reactions to these perceptions and found that psychologically entitled employees are prone to feel that they are victims of abuse and to react in undesirable ways. Frieder et al. [26] studied the factors that weaken the negative emotional and behavioral responses generated by abusive supervision, and suggested that individuals show proactive behaviors in speaking, so that they can manage their resources better than those who do not when faced with abuse from their superiors, and they will experience less dissatisfaction, emotional exhaustion, and turnover intention. This study explored that personal factors can reduce the harmful effects of abusive supervision through the extended support from demand-control model. This article argued that highly resource management ability (RMA) individuals and active advice can alleviate the abuse of superiors because they have personal control options (i.e. advice) and control beliefs (i.e. perceived resource management ability). Sager et al. [27] proposed and tested a downward abusive communication model. According to the model, abusive communication between superiors and subordinates is caused by a lack of downward communication adaptability. Senior executives from various organizations completed an online survey that measured their downward communicative adaptability and downward abusive communication. The results of this study suggest that the ability to adapt to communication can promote the constructive mode of interaction, which is a step to prevent abusive supervision in the workplace. As far as organizational leaders are concerned, they need to realize that if they want to make long-term changes in the interaction model between superiors and subordinates, they must have good communication and adaptability. Eissa and Lester [28] believed that neuroticism is expected to moderate the relationship between role overload and frustration while conscientiousness and agreeableness are expected to moderate the relationship between frustration and abusive supervision.

\section{Main Research Methods}

In the researches of the impact of abusive supervision on employees and the 
coping methods of abusive supervision, the process of research and analysis is the key to understanding the various characteristics of abusive supervision. In general, these studies analyzed and tested from different theoretical perspectives. For example, Gao He et al. [5] studied the impact and role of abusive supervision on job performance in China's high right distance and high collectivist cultural environment based on a two-factor theoretical basis. Henle and Gross [10] found that emotional stability and responsibility negatively predict employee abusive supervision according to the victim precipitation theory, and this relationship is mediated by negative emotions. Wu and Lee [12] used the theory of resource conservation to explore the impact of abusive supervision on psychological capital and the factors that affect knowledge sharing. Palanski et al. [20] examined the role of moral leadership and abusive supervision in the process of resignation by using the information disclosure expansion model and the dual process theory of information processing. The main research methods used in these literatures include empirical research and model analysis, include sampling, hypothesis test, questionnaire survey and regression analysis and other specific methods, in addition to the case data research. For example, Khan et al. [22] conducted regression analysis and hypothesis test with data of 173 subordinates and 45 supervisors from different private sector organizations in Pakistan. Yan Aimin and Pei Cong [6] used the analytic hierarchy process to analyze 241 questionnaire data from enterprise employees in central and southern China. Xi Yanping [21] took 283 full-time employees in three provinces as the empirical research object, and used a structural equation model to test the research hypothesis. Gao He et al. [5] used the structural equation model and hierarchical regression method to explore the impact mechanism of abusive supervision on job performance, and empirical researched with 265 financial institution employees and college MBA students. Palanski et al. [20] examined the role of moral leadership and abusive supervision in the process of resignation by using the information disclosure expansion model and the dual process theory of information processing. Vogel et al. [16] conducted a cross-sectional study design that analyzed the survey data of 150 employees from the public, private, and non-profit sectors in Germany and the United States.

\section{Conclusions and Prospects}

With the continuous emergence of abusive supervision in reality and the development of related research in theory, in recent years, research on the impact and coping methods of abusive supervision has continued to deepen. In terms of main research scope, the research on the impact of abusive supervision on employees is basically around the relationships of abusive supervision and some factors such as employee innovation and performance, employee satisfaction and emotion, employee knowledge sharing, employee deviance or anti-production behavior, and employee turnover intentions. In addition, some studies have explored the positive impact of abusive supervision in a certain sense. The research 
on coping methods of abusive supervision basically analyzed from the perspective of leaders or subordinates. In terms of main research contents and results, these research results mainly show that the abusive supervision has a negative impact on employee innovation and performance, employee satisfaction and emotion, and employee knowledge sharing, while it is positively related to deviant or anti-production behaviors and turnover intention of employees. In addition, from the perspective of individual differences and employee psychology, by changing the state of employees' perception of danger and organizational identity, the abusive supervision in the organization can have positive effects such as improving employee performance. Finally, people can effectively deal with the negative problems brought by abusive supervision through the active expression and suggestion behavior of subordinates and good downward communication of superiors. In terms of research methods, these studies basically combined different theories and analyzed or tested the actual survey data on the basis of theoretical analysis.

The main contributions of this paper are: summarizing the frontier research results and research characteristics of abusive management issues, putting forward its future research space, and making efforts to improve the abusive management research system and solving the abusive management problems in organizations in practice.

Although the existing researches on the impact and the coping methods of abusive supervision have gradually been enriched, there are still some shortcomings in this research area. Firstly, in terms of the impact of abusive supervision on employees, the existing research has not studied the cross influence of multiple factors in complex situations. In addition, the research on the impact of abusive supervision mainly focused on the individual level; there are relatively few studies focusing on the impact of abusive supervision on the team or organization level. Besides, there are a few researches in the term of the coping methods for abusive supervision at present; also, no systematic framework has been formed, and no specific research has been done on the specific coping mechanisms. Therefore, there is still a lot of research space in this field worthy of further exploration.

In the future research, researchers can study the impact and coping methods of abusive supervision in organizations from the level of individuals, teams, and organizations, and use models to establish specific mechanisms and corresponding processing mechanisms, so that it can guide and deal with relevant problems in practice more effectively. In addition, as China's research in this field is not yet complete, further researches of abusive supervision can be based on China's specific environmental conditions and development stages.

\section{Conflicts of Interest}

The author declares no conflicts of interest regarding the publication of this paper. 


\section{References}

[1] Tepper, B.J. (2000) Consequences of Abusive Supervision. The Academy of Management Journal, 43, 178-190. https://www.jstor.org/stable/1556375 https://doi.org/10.2307/1556375

[2] Lee, S., Yun, S. and Srivastava, A. (2013) Evidence for a Curvilinear Relationship between Abusive Supervision and Creativity in South Korea. Leadership Quarterly, 24, 724-731. https://doi.org/10.1016/j.leaqua.2013.07.002

[3] Khusbu, R., Donghong, D. and Nisha, R. (2017) Understanding the Role of Creative Self-Efficacy and Power Distance Orientation for Examining the Consequences of Abusive Supervision on Employee Creativity: A Case Study from Nepal. Open Journal of Leadership, 6, 61-81. https://doi.org/10.4236/oj1.2017.62004

[4] Lyu, Y., Zhou, X., Li, W., Wan, J. and Qiu, C. (2016) The Impact of Abusive Supervision on Service Employees' Proactive Customer Service Performance in the Hotel Industry. International Journal of Contemporary Hospitality Management, 28, 1992-2012. https://www.researchgate.net/publication/309091903 https://doi.org/10.1108/IJCHM-03-2015-0128

[5] Gao, H., Li, T.T. and Duan, H. (2016) An Empirical Study on the Impact of Abusive Supervision on Job Performance: Mediating Role of Job Satisfaction and Moderating Role of Core Self-Evaluation. Enterprise Economics, 429, 106-112. http://www.cnki.com.cn/Article/CJFDTotal-QUIT201605016.htm

[6] Yan, A.M. and Pei, C. (2013) The Influence of Abusive Supervision on Job Performance and the Mediating Effect of Self-Efficacy. Journal of Management, 10, 213. http://www.cnki.com.cn/Article/CJFDTotal-GLXB201302011.htm

[7] Yu, W.N., Fan, Y., Zhang, J. and Men, Y. (2015) The Impact of Abusive Supervision on Work Performance from the Perspective of Forgiveness: The Role of Subordinate Tradition and Superior Subordinate Relationship. Nankai Management Review, 105, 18-27. http://www.cnki.com.cn/Article/CJFDTotal-LKGP201506004.htm

[8] Lin, W., Wang, L. and Chen, S. (2013) Abusive Supervision and Employee Well-Being: The Moderating Effect of Power Distance Orientation. Applied Psychology, 62, 308-329. https://www.researchgate.net/publication/263140293 https://doi.org/10.1111/j.1464-0597.2012.00520.x

[9] Jiang, W., Wang, L. and Lin, H. (2016) The Role of Cognitive Processes and Individual Differences in the Relationship between Abusive Supervision and Employee Career Satisfaction. Personality and Individual Differences, 99, 155-160. https://www.sciencedirect.com/science/article/abs/pii/S0191886916303488 https://doi.org/10.1016/j.paid.2016.04.088

[10] Henle, C.A. and Gross, M.A. (2014) What Have I Done to Deserve This? Effects of Employee Personality and Emotion on Abusive Supervision. Journal of Business Ethics, 122, 461-474. https://link.springer.com/article/10.1007/s10551-013-1771-6 https://doi.org/10.1007/s10551-013-1771-6

[11] Ogunfowora, B. (2013) When the Abuse Is Unevenly Distributed: The Effects of Abusive Supervision Variability on Work Attitudes and Behaviors. Journal of Organizational Behavior, 34, 1105-1123. https://doi.org/10.1002/job.1841 https://www.researchgate.net/publication/259683183

[12] Wu, W.L. and Lee. Y.C. (2016) Do Employees Share Knowledge When Encountering Abusive Supervision? Journal of Managerial Psychology, 31, 154-168. https://doi.org/10.1108/JMP-12-2013-0410

[13] Kim, S.L., Kim, M. and Yun, S. (2015) Knowledge Sharing, Abusive Supervision, 
and Support: A Social Exchange Perspective. Group \& Organization Management, 40, 599-624. https://doi.org/10.1177/1059601115577514 https://www.onacademic.com/detail/journal_1000037796608610_9cbd.html

[14] Kim, S.L., Lee, S. and Yun, S. (2016) Abusive Supervision, Knowledge Sharing, and Individual Factors: A Conservation-of-Resources Perspective. Journal of Managerial Psychology, 31, 1106-1120. https://doi.org/10.1108/JMP-05-2015-0169

[15] Wei, F. and Si, S. (2013) Tit for Tat? Abusive Supervision and Counterproductive Work Behaviors: The Moderating Effects of Locus of Control and Perceived Mobility. Asia Pacific Journal of Management, 30, 281-296. https:/link.springer.com/article/10.1007/s10490-011-9251-y

[16] Vogel, R., Homberg, F. and Gericke, A. (2016) Abusive Supervision, Public Service Motivation, and Employee Deviance: The Moderating Role of Employment Sector. Evidence-Based HRM: A Global Forum for Empirical Scholarship, 4, 214-231. https://www.researchgate.net/publication/311259543 https://doi.org/10.1108/EBHRM-08-2015-0034

[17] Michel, J.S., Newness, K. and Duniewicz, K. (2016) How Abusive Supervision Affects Workplace Deviance: A Moderated-Mediation Examination of Aggressiveness and Work-Related Negative Affect. Journal of Business and Psychology, 31, 1-22. https://link.springer.com/article/10.1007/s10869-015-9400-2 https://doi.org/10.1007/s10869-015-9400-2

[18] Ma, Y.Q., Xi, M., Xu, Q. and Zhao, S. (2017) A Study on the Mechanism of Abusive Supervision on Subordinates' Anti-Production Behavior Based on Social Cognitive Theory. Journal of Management, No. 8, 1153-1161. http://www.cnki.com.cn/Article/CJFDTOTAL-GLXB201708008.htm

[19] Mathieu, C. and Babiak, P. (2016) Corporate Psychopathy and Abusive Supervision: Their Influence on Employees' Job Satisfaction and Turnover Intentions. Personality and Individual Differences, 91, 102-106. https://www.sciencedirect.com/science/article/abs/pii/S0191886915300830 https://doi.org/10.1016/j.paid.2015.12.002

[20] Palanski, M., Avey, J.B. and Jiraporn, N. (2014) The Effects of Ethical Leadership and Abusive Supervision on Job Search Behaviors in the Turnover Process. Journal of Business Ethics, 121, 135-146. https://doi.org/10.1007/s10551-013-1690-6

[21] Xi, Y.P. (2016) Research on the Impact of Abusive Supervision on Employee Turnover Intention: Multiple Mediating Effects of Emotional Exhaustion and Employees' Trust to Supervisors. Technology Economy and Management Research, No. 12, 51-55. http://www.cnki.com.cn/Article/CJFDTotal-JXJG201612010.htm

[22] Khan, A.K., et al. (2017) Double Jeopardy: Subordinates' Worldviews and Poor Performance as Predictors of Abusive Supervision. Journal of Business and Psychology, 32, 165-178. https://doi.org/10.1007/s10869-016-9442-0

[23] Decoster, S., Camps, J., Stouten, J., Vandevyvere, L. and Tripp, T.M. (2013) Standing by Your Organization: The Impact of Organizational Identification and Abusive Supervision on Followers' Perceived Cohesion and Tendency to Gossip. Journal of Business Ethics, 118, 623-634. https://doi.org/10.1007/s10551-012-1612-z https://link.springer.com/article/10.1007/s10551-012-1612-z

[24] Harvey, P., Stoner, J., Hochwarter, W. and Kacmar, C. (2007) Coping with Abusive Supervision: The Neutralizing Effects of Ingratiation and Positive Affect on Negative Employee Outcomes. The Leadership Quarterly, 18, 264-280.

https://www.researchgate.net/publication/222826748

https://doi.org/10.1016/j.leaqua.2007.03.008 
[25] Harvey, P., Harris, K.J., Gillis, W.E. and Martinko, M.J. (2014) Abusive Supervision and the Entitled Employee. The Leadership Quarterly, 25, 204-217.

https://www.researchgate.net/publication/259142024 https://doi.org/10.1016/j.leaqua.2013.08.001

[26] Frieder, R.E., Hochwarter, W.A. and Deortentiis, P.S. (2015) Attenuating the Negative Effects of Abusive Supervision: The Role of Proactive Voice Behavior and Resource Management Ability. The Leadership Quarterly, 26, 821-837.

https://www.sciencedirect.com/science/article/pii/S1048984315000673 https://doi.org/10.1016/j.leaqua.2015.06.001

[27] Sager, K.L., Wallace, E.A., Jarrett, B. and Richey, J.A. (2015) Exploring the Role of Communication Competence in Abusive Supervision: A Test of a Model Linking Downward Communicative Adaptability to Downward Abusive Communication. SAGE Open, 5. https://www.researchgate.net/publication/282511035 https://doi.org/10.1177/2158244015604689

[28] Eissa, G. and Lester, S.W. (2017) Supervisor Role Overload and Frustration as Antecedents of Abusive Supervision: The Moderating Role of Supervisor Personality. Journal of Organizational Behavior, 38, 307-326.

https://onlinelibrary.wiley.com/doi/abs/10.1002/job.2123 https://doi.org/10.1002/job.2123 